\title{
Getting Feedback on Defined Contribution Pension Plans
}

\author{
Bonnie-Jeanne MacDonald* Andrew J.G. Cairns ${ }^{\dagger}$
}

\begin{abstract}
With the growth of private and public DC pension plans around the world, market rates of return should increasingly play a large role in the retirement patterns of individuals. The reverse could, however, also be true - that is, a country's population demographics could influence the financial markets. In this paper, we model the potential impact of aggregate retirement patterns on macroeconomic variables with the goal of further understanding the implications of a traditional DC pension becoming the predominant source of retirement income for an entire society. We find that feedback in the economic system resulting from changing asset demand of DC plan members dampens fluctuations in the size of the retired population.
\end{abstract}

Keywords: Defined-contribution pension plan; financial marketfeedback; stochastic simulation.

* Bonnie-Jeanne MacDonald is a Postdoctoral Fellow at the Department of Statistics and Actuarial Science, University of Waterloo, Waterloo, Ontario, N2L 3G1, Canada, Email: BonnieJeanne_MacDonald@hotmail.com

${ }^{\dagger}$ Prof Andrew J.G. Cairns is the Professor of Financial Mathematics, Maxwell Institute for Mathematical Sciences and Department of Actuarial Mathematics and Statistics, School of Mathematical and Computer Sciences, Heriot-Watt University, Edinburgh, EH14 4AS, U.K., Phone: +44 (0) 131451 3245, Fax: +44 (0) 131451 3249, Email: A.Cairns@ma.hw.ac.uk 


\section{Introduction}

With the growth of DC pension plans around the world, in both the private pensions and public systems, market rates of return are increasingly likely to play a large role in the retirement patterns of individuals, however, the reverse could also be true (MacDonald and Cairns, 2006). A variety of existing theoretical economic models claim that "demographics matter" (Poterba, 2004); that is, the demographic structure of a population could affect financial markets. The benefit of this paper is that we model, for a population-wide DC pension system, the dynamic interaction among the retirement patterns of the population, aggregate demand for assets and financial market returns, as well as between the aggregate supply of workers and general wage growth. We refer to this as "modeling feedback".

This is a companion paper to MacDonald and Cairns (2006), which examined the labour force implications of a nation-wide pure DC pension system. Using the simulated output from a modelled society populated by DC plan participants, they found that market performance plays an important role in the retirement pattern of workers and creates instability in the ratio of retirees to workers (dependency ratio) from one year to the next. The objective of this paper is to incorporate a simple macroeconomic feedback feature into the stochastic simulation model of MacDonald and Cairns (2006) and investigate its effects. If the population's retirement patterns do indeed impact the financial rates of return and wages, this feedback could potentially dampen or exacerbate the swings in the dependency ratio.

There has been a growing interest in the relationship between changing demographics and the impact on financial market returns. The focus of the majority of the literature has been the response of the financial market to the baby-boom; more precisely, has explored how changing age cohort sizes create a change in asset demand and the associated impact on the financial returns. Such studies are motivated by the demographic transition occurring in the US and in many other developed countries.

Unlike these previous studies, we assume a stationary and stable population model. Rather than the age structure, it is the level of labour force participation in our population that varies and affects the financial asset demand, which could then affect the equilibrium of the financial market. Although modeling changes in the population size and age structure distribution is an interesting topic for future work, this paper examines only a stationary population model in order to clarify the implications of a pure DC pension system on interaction between the 
workforce demographics and economic variables, and to distinguish this impact from the effects of shifts in the demographic age structure.

Despite the constant age structure in our model, previous age structure studies have provided several insights that have contributed to our feedback model and our general analysis. In the coming section, we provide a brief review of the findings that have helped us in our investigation.

We divide our paper into four parts. Section 2 discusses the previous literature on the relationship between financial market returns, demographics and asset demand in the context of our analysis. Section 3 outlines the stochastic economic model, which is a summary of the model described in MacDonald and Cairns (2006) with the addition of a few new elements. Section 4 describes the feedback model. Section 5 proceeds by discussing the results of the simulated feedback model. Finally, we provide our conclusions.

\section{Previous Literature on the Aggregate Impact of Asset Demand on Financial Markets}

This section discusses previous literature whose aim was to examine the potential impact of demographic shocks on the equilibrium asset returns. Although the studies are not completely applicable to our analysis, they provide insight into:

- the theoretical effect of retirement savings behavior on financial market returns;

- other retirement-related feedback that could dampen the financial market impact; and

- the potential influence on the types of assets in demand.

These findings shape our analysis, as we elaborate on at the end of this section.

Numerous studies have examined the relationship among demographic variables, the demand for assets and financial market returns. A summary of both empirical and model-based attempts can be found in Poterba et al. (2005). This type of research is similar to our objectives since it investigates the possible repercussions in the financial market returns caused by shocks in the aggregate asset demand, which is measured by the proportion of the population in their asset accumulation years and those in their draw-down years. Our model attributes an 
individual's savings profile to their retirement status, whereas the previous studies mostly linked it to his/her age. For example, ages 40-60 are treated as prime saving years, while any individual above this age is considered "retired" and is expected to reduce their asset holdings. This age pattern of asset ownership follows what is called a "life-cycle" behavior. During the baby boom generation's transition from one age class to another, it is suggested that there would be significant changes in their demand for assets, with corresponding effects on market returns. These baby-boom studies have included population age structure simulations that resemble the demographic transition in the United States during the last four decades. An example of this type is Brooks (2002) who simulated the assetmarket response to recent changes in the US population structure. There also exist a number of empirical studies on the demographic shocks that have occurred in one or several countries. Ang and Maddaloni (2003) carried out such a study and examined US time series data, along with 14 other developed countries, to explore the potential impact of demographic changes on asset returns.

There are helpful portions of these studies and parts not applicable. First, we are unable to make use of the feedback models developed in previous studies since they generally measure the financial market's response to a changing age structure. In our stable and stationary population model, we assume a member's ability to save is linked to their employment status and not their age. Having a flexible retirement age model, it is the instability between age and retirement status for a member in a DC plan that is the cornerstone of our study. Secondly, although the choice to continue participating in the labour market is certainly age-related, the age and labour force participation structures of a population could potentially not have the same influence on returns in the economy. Had the previous studies investigated the effects of the working and retired portions of the population rather than the age demographics, the findings could have been different since:

- Employment status is often linked to age in a simple fashion as, for example, in Ang and Maddaloni (2003) where age classes above 60 are classified as being retired. In practice, however, employment status could be linked to a variety of other factors. In fact, the participation rates for 55 to 64 year-olds in the labour force vary widely at present across G10 countries, from the high twenties (percent) to the low seventies, according to a report prepared at the request of the Deputies of the Group of Ten by an experts group chaired by Ignazio Visco (OECD, 2005).

- As explained by Poterba et al. (2005), there would be some degree of foresight regarding demographic age structure shifts. If associated sharp 
changes in asset prices could be anticipated, traders could profit by going long or short in advance depending on the direction of the shift. Since demographic shocks in the age-structure of wealth-holdings occur gradually and with long lead times, it is doubtful that there would be a sharp change in asset price over a short period of time. In our model, however, retirement patterns are quite unpredictable, making it difficult for traders to have foresight regarding the shifts in the financial asset demand linked to the wealth holdings of a changing labour force size. This difference leads to the possibility that sharp changes in asset prices could occur in our economic system.

Despite the differences, this previous literature provides crucial insights into the relationship among retirement patterns and the financial market. The widespread theoretical effect would suggest a rise in asset prices as more members of the population save for retirement and, conversely, the retirement of a significant share of the population would put a downward pressure on asset prices (Poterba, 2004). Nevertheless, studies have also pointed to other sources of feedback that could potentially alleviate this impact by moving the supply of assets in the same direction as demand without necessarily affecting their pricing. These include:

- a flexible supply of capital, which means that the price of capital goods would affect the growth of capital stock (Poterba, 2004),

- international capital flows, which allows for a more elastic supply of capital (Poterba, 2004) and

- the correlation between domestic investment opportunities and labour force growth.

The last point, explained by Bosworth et al. (2004), suggests that, as more individuals retire and draw down their retirement savings, the declining rate of labour force growth would reduce domestic investment opportunities since employers would have less need to provide new equipment and facilities for additional workers. The reverse could also occur. The availability of domestic investments associated with the growth in the labour, therefore, move to partly mirror the growth in national savings.

A second point raised in this body of research is the change in the types of financial assets that individuals would demand owing to new retirement patterns (Poterba, 2004). That is, a large working portion of the population could place an emphasis on equity assets and then, upon their retirement, the emphasis could 
shift to a demand for financial assets that preserve wealth, such as bonds and annuity contracts. If individuals adjust their investment strategies, however, on account of their age rather than their retirement status, then asset ownership preferences among age groups is the leading cause behind the demand for the various financial assets and the associated effects on the financial market returns. This particular concern would thus be less of an issue in our economy model since we are assuming a stationary and stable population model where annuitization at retirement is not obligatory. If an individual's investment strategy is linked to their retirement status, however, then our study should take this possible repercussion into consideration.

The remarks above help to shape our analysis. The widespread theoretical effect is the basis of our feedback model that Section 4 will outline. In Section 5, the potential sources of feedback that could help to maintain the asset equilibrium prompts an examination of multiple feedback scenarios:

- fixed supply of capital; and

- two levels of flexibility in the supply.

Testing various levels of feedback is further justified by the uncertainty and inconsistency of the conclusions drawn from previous studies. Poterba (2004) explained that the magnitude of the suggested relationship between the population's demographics and asset returns has been mixed among previous empirical studies and varies among the mathematical models that have been developed.

Furthermore, the possibility that individuals would choose to revise their portfolios at retirement by adopting a less risky investment strategy leads us to consider two asset investment scenarios. In the first case, we will specify that all members move their accumulated pension funds to a less risky asset at retirement. The second scenario will assume that the member's investment proportions remain fixed throughout their lifetime. We will refer to these as the static and non-static investment strategies:

Non-static investment strategy: the workers' assets are reallocated to indexlinked bonds on retirement, irrespective of their investment strategy during employment and

Static investment strategy: the investment strategies of the participants are unchanging throughout their lifetimes. 


\section{Model and Assumptions}

To model the macroeconomic feedback in a society populated by DC plan participants, we build on the stochastic simulation model developed in MacDonald and Cairns (2006). The details of the model and the parameter estimation process were given in that paper. We refer to this initial model, which is without the feedback feature, as the "original" model. We review here the key assumptions:

- Every individual in the population is a member of the same DC pension system, which is their only source of retirement income.

- The DC pension system has a "pure" design, so there are no ancillary benefits such as a minimum pension guarantee. There are also no constraints on the members, such as a minimum period of enrollment for vesting, a mandatory retirement age or annuitization requirement after retirement.

- The economic processes in the financial model are stochastic and are underpinned by the Vasicek model (1977). The economic model integrates the workers' salary growth, inflation, annuitization rates and financial asset returns.

- In the original model, an individual's wage growth is made-up of inflation, real wage growth and a merit component. The first two items are modeled stochastically as a part of the economic model, while the last item is a deterministic function of age.

- Each individual in the population begins employment at age 20, enters the pension plan at age 25 , then makes an annual $10 \%$ salary contribution to their DC plan.

- There are neither taxes, expenses, nor allowances for profit in the financial assets' pricing and the management of the DC plan.

- The gender structure of the DC population is implicitly irrelevant since the details of the model are gender neutral. We assume blended mortality rates: $50 \%$ male and 50\% female based on the United States Life Tables 2002 for females and males (Arias, 2004). The change in the results from the added complication of sex-specific mortality would be modest and inconsequential to our general conclusions. In addition, a member's approach to the retirement decision is not affected by their gender. 
- We consider retirement to be an absorbing state and retired members cannot reenter the workforce.

In the original model, the workers invested across five assets. To simplify the illustration of the feedback, we assume that workers allocate their wealth between a risky and a low-risk asset. Thus, we choose equities and index-linked bonds as the available assets for investment. MacDonald and Cairns (2006) came to the same conclusions as Lachance (2003) in showing equity to be an extremely beneficial pension investment for a worker with a flexible retirement age. MacDonald and Cairns (2006) also found that a homogeneous index-linked bond investment strategy for a population of DC members generates the least amount of risk in the dependency ratio (ratio of workers to retirees), and therefore is the lowest risk investment from an aggregate perspective. Furthermore, index-linked bonds benefit the retired member not only by preserving wealth owing to the low volatility of their returns, but they also help to maintain the retired member's standard of living since the coupon and principal payments are adjusted to compensate for changes in inflation. In other words, they preserve wealth in real terms. We test each of the two assets at $10 \%$ increments, creating a total of eleven portfolios available for investment.

As we explain above, we test two asset-allocation strategies among the participants. In the first scenario, the funds are moved to the less risky asset at retirement, whereas the second scenario assumes a static investment strategy. A member with a static investment strategy maintains constant proportions of each asset in their portfolio throughout their lifetime, thus rebalancing the portfolio at the end of each year. This is important to note since the movement of assets from rebalancing is a source of asset demand in the feedback model. In addition, the change of asset strategy on retirement in the first scenario also creates a source of asset demand, thereby generating feedback. While the funds are invested, we assume the members will continuously reinvest any payments earned from their investments.

Some features of our model are simplistic while others are more sophisticated. For example, in each scenario of this study, we assume a homogeneous investment strategy across the population. This feature could seem unrealistic since there exists tremendous diversity among the portfolios of investors in the real world. A large part of the analysis in MacDonald and Cairns (2006) was the search for realistic model improvements that would successfully dampen the severe dependency ratio volatility that they observed when simulating the dynamics of a population of DC members over time. They had found that assuming various investment strategies did little to improve the dependency ratio's volatility 
owing to the high correlation between the smoothed long-term rates of return on different asset classes. They had experimented with non-homogeneous asset allocation decisions across the population, as well as dynamic investment strategies that change over the participants' lifetimes - both deterministic and stochastic such as the popular "lifestyle" asset allocation strategy (see MacDonald (2007) for more details on this last analysis). In addition to the investment strategy, heterogeneity was introduced into the participants' contribution rate, plan enrollment age and career flight path, but none of this diversity was found to reduce volatility to any significant extent.

In the course of this paper's analysis, we also investigated two other retirement decision-making models for the population members. They were the two-thirds and the option-value (Stock and Wise, 1990) retirement models, whose parameters and details were given in MacDonald (2007). The influence of the feedback model on the population dynamics was nearly identical across all three models.

\subsection{Retirement Decision Model}

We assume the population's retirement decision-making follows the myopic retirement model. Below is a brief summary - this retirement decision model was explored in more detail in MacDonald (2007) ${ }^{1}$.

At retirement, the pension that a worker can purchase is set to equal the accumulated pension wealth, $W(t)$, divided by a fixed life annuity factor, $\ddot{a}_{x}(t)$ :

$$
\ddot{a}_{x}(t)=\sum_{s=t}^{\infty} P_{1}\left(x_{1}(t), t, s\right)_{s-t} \mathrm{p}_{x},
$$

where

$t$ : current time;

$x$ : member's current age;

${ }_{s-t} \mathrm{p}_{x}$ : probability of survival in the next $s-t$ years for someone aged $x$;

$P_{1}\left(x_{1}(t), t, s\right)$ : the price at time $t$ of a risk-free zero-coupon bond that matures at time $s$; and

$x_{1}(t)$ : the instantaneous risk-free rate of interest at time $t$.

\footnotetext{
${ }^{1}$ This model was slightly altered in later work but the main features of the model remained the same.
} 
The stochastic state variable, $x_{1}(t)$, follows the Vasicek model (1977), as does the bond-pricing formula for $P_{1}\left(x_{1}(t), t, t+s\right)$. A full description of the stochastic asset-return model and salary model, including the parameter estimates and the sources of data, were given in MacDonald and Cairns (2006).

In the myopic retirement model, retirement occurs once the discounted utility value of immediate retirement at time $t$ :

$$
V^{t}(t)=\mathrm{L}+\sum_{s=t}^{\infty} \beta(t, s)_{s-t} \mathrm{p}_{x} U_{r}\left(\frac{C^{t}(s)}{Y(t)}\right),
$$

outweighs the discounted utility value of retiring at time $t+1$ :

$$
V^{t+1}(t)=U_{w}\left(\frac{C(t)}{Y(t)}\right)+\sum_{s=t+1}^{\infty} \beta(t, s)_{s-t} \mathrm{p}_{x} U_{r}\left(\frac{C^{t+1}(s)}{Y(t)}\right)+\beta(t, t+1)_{1} \mathrm{p}_{x} \mathrm{~L},
$$

where:

$t$ : current time;

$Y(t)$ : the worker's salary at time $t$.

$V^{R}(t)$ : discounted utility value function at time $t$ conditional on retirement at time $R$

$\beta(t, s)$ : personal discount factor between times $t$ and $s\left(=P_{1}\left(x_{1}(t), t, s\right)\right)$;

$C(s)$ : consumption at time $s$ while working $(=(1-\pi) Y(s)$, where $\pi$ represents the contribution rate);

$C^{R}(s)$ : pension consumption at time $s$ conditional on retirement at time $R$ (= $\left.W(R) / \ddot{a}_{x+R-t}(R)\right)$

$U_{w}(c)$ : utility function of future wage income;

$U_{r}(c)$ : utility function of future retirement benefit income;

$L$ : utility value of retirement leisure (fixed parameter).

The power utility function of consumption both during employment and after retirement are parameterized as:

$$
U_{w}\left(\frac{C(s)}{Y(t)}\right)=\frac{(C(s) / Y(t))^{\gamma}}{\gamma}
$$


and

$$
U_{r}\left(\frac{C^{R}(s)}{Y(t)}\right)=\frac{\left(C^{R}(s) / Y(t)\right)^{\gamma}}{\gamma} .
$$

where $1-\gamma$ is the relative risk aversion (fixed parameter). The utility of future consumption is considered relative to current salary, $Y(t)$ (that is, $C^{t+1}(s) / Y(t)$, $C^{t}(s) / Y(t)$, and $C(s) / Y(t)$ rather than $C^{t+1}(s), C^{t}(s)$ and $\left.C(s)\right)$. This emphasizes the importance of preserving the worker's standard of living at retirement and, from a modeling perspective, prevents salary inflation from corroding the fixed utility gained from leisure, $L$, with the passing of time. The parameter estimates are $L=23$ and $\gamma=-0.75$.

\subsection{Population Model}

The age structure of the population is stable and stationary. There are 81 age groups in the population at all times, ranging from the age of employment $\left(x_{e}=\right.$ $20)$ to age 100 , which is taken to be the ultimate age in the mortality table $\left(x_{u}=\right.$ $100)$. The relative size of each age group $x$, whose members are age $x$, is labeled $l_{x}$ :

$$
l_{x}={ }_{x-x_{e}} \mathrm{p}_{x_{e}} .
$$

$l_{x_{u}+1}=0$.

The retirement dynamics of the population are measured by the dependency ratio. Of the many definitions for dependency ratio, the one used in this study is the ratio of the number of retirees to the number of workers.

$$
\text { Dependency Ratio }=\frac{\# \text { retired population }}{\# \text { working population }} \text {. }
$$

The dependency ratio is calculated for every year of simulation and is based on the proportional sizes of the groups. In the context of our model, a high dependency ratio indicates that workers are able to afford an early retirement with their DC pension funds. Conversely, a low dependency ratio signifies that poor historical investment returns have been causing older workers to defer retirement.

Let $W_{x}(t)$ be the accumulated pension wealth of an individual aged $x$ and, accordingly, in age group $x$. From year to year, the members move from one age group to the next. The proportional total fund of all 81 age groups at time $t$ is then:

$$
\sum_{x=x_{e}}^{x=x_{u}} \mathrm{~W}_{x}(t) l_{x}
$$


We use this last formula to compare the aggregate invested wealth between years.

\subsection{Decumulation of Assets}

We require an assumption regarding pension wealth decumulation after retirement to track the member's asset demand after exiting the workforce. It is common for DC style accounts in the state pension system to have maximum and minimum annual withdrawals to prevent pensioners from running out of funds or evading taxes. One method of calculating the maximum in each retirement year is to divide the total wealth by a level life annuity based on the pensioner's current age. If a pensioner were to withdraw according to the maximum, however, the pension in each consecutive year would decrease by inflation and mortality in addition to any gains or losses on the fund's rate of return. To help compensate for the otherwise large decrements in the pension income, we assume the pensioners withdraw an amount equal to having purchased an annuity with inflation protection. With this assumption, the next formula describes the wealth decumulation in each year of retirement:

$$
\mathrm{W}_{x}(t)=\mathrm{W}_{x-1}(t-1)(1+i(t))\left(1-1 / \ddot{a}_{x-1}^{x_{3}(t-1)}(t-1)\right),
$$

where $i(t)$ is the investment return earned on the fund between times $t-1$ and $t$. At time $t-1$, the value of an annuity factor that incorporates the provision to index a pensioner's income by inflation is represented by:

$$
\ddot{a}_{x-1}^{x_{3}(t-1)}(t-1)=\sum_{s=0}^{\infty} P_{3}\left(x_{3}(t-1), t-1, t-1+s\right){ }_{s} \mathrm{p}_{x-1} .
$$

$P_{3}\left(x_{3}(t), t, T\right)$ is similar to $P_{1}\left(x_{1}(t), t, T\right)$, except yielding a real rate of interest. $C P I(t) P_{3}\left(x_{3}(t), t, T\right)$ is the price at time $t$ of a zero-coupon index-linked bond that pays $C P I(T)$, the consumer price index, at time $T$. The stochastic state variable, $x_{3}(t)$, is the instantaneous real risk-free rate of interest at time $t$ and, like $x_{1}(t)$, it follows the Vasicek (1977) model.

There has been a near absence of voluntary annuitization in the US (Brown and Warshawsky, 2001; Davidoff et al., 2005), justifying why we do not make this assumption here. For those who do not annuitize, Poterba et al. (2005) reported that there has been little empirical analysis on the timing or frequency of pension account balance draw-downs. Similar to our study, Poterba et al. (2005) aimed to understand the impact of future demographic trends on the demand for assets. 
To do so, they also made a withdrawal assumption to project the future pension funds in 401(k) DC pension accounts of US citizens. Admitting it to be a crude withdrawal scheme, they assumed that the annual withdrawal was 2 percent of the member's account balance between ages 65 and 71.5, becoming (1/Remaining Life Expectancy) times the 401(k) balance at older ages. This withdrawal scheme took into account both the size of the remaining fund and the expected life span of the participants. On top of these two considerations, our model also incorporates current economic conditions through the use of the prevailing real interest rate. This stochastic component both integrates the pension withdrawal level with the rest of the asset model, as well as adds variety in the proportion of pension withdrawal from year to year among the age groups. Finally, the pension income of our decumulation model is expected to decline somewhat in real terms as the individual ages owing to the mortality decrement, which could be a reasonable assumption since financial needs are thought to decline with age. Several examples of such expenses were provided in the retirement needs model of McGill et al. (1996).

\subsection{Withdrawals from Death}

To model the possible link among the retirement patterns, associated asset demand and financial market returns, we must account for all assets at all times so that they are factored into the change in demand. We require an assumption, therefore, concerning the disposal of assets belonging to the deceased. We assume that the deceased have a bequest motive and we consider two inheritance decision models.

In the first inheritance decision model, the assets of the deceased are simply distributed evenly across their respective age groups, who then add this inheritance to their pension savings. To allow for this, each surviving member's savings are increased by $1 /{ }_{1} \mathrm{p}_{x}$ between ages $x$ and $x+1$. This is equivalent to the concept of survivor credits proposed by Blake et al. $(2003)^{2}$. It is also equivalent to the pooling achieved by full annuitisation at the time of retirement.

In the second scenario, the assets of the deceased are distributed evenly to the survivors aged 20 to age 55. From their inheritance, the recipients allocate $10 \%$ to their retirement accounts; thus, there is a $90 \%$ leakage of bequests. In other words, recipients of bequests liquidate $90 \%$ of their inherited assets to use for

\footnotetext{
${ }^{2}$ The extent to which actual survivorship differs from $1 \mathrm{p}_{x}$ means that there is some leakage of assets in the real world. In a large population, however, this leakage is small in comparison to the general movement of money. Irrespective, there is no leakage in our simulations since we assume a fixed mortality table for the population members.
} 
other purposes, such as the repayment of debt or taking a vacation. To illustrate using notation given in Sections 3.2 and 3.3, the proportional total inheritance of all 81 age groups that becomes available between times $t-1$ and $t$ is:

$$
\sum_{x=x_{e}}^{x=x_{u}} \mathrm{~W}_{x}(t-1)(1+i(t)) l_{x} 1 \mathrm{q}_{x} .
$$

Between years $t-1$ and $t$, each member in age groups $\mathrm{x}=20$ to 55 at time $t$ equally receive a portion of the wealth of the deceased - this portion equals:

$$
\sum_{x=x_{e}}^{x=x_{u}} \mathrm{~W}_{x}(t-1)(1+i(t)) l_{x} \mathrm{q}_{x} / \sum_{x=20}^{x=55} l_{x},
$$

$10 \%$ of which is added to the recipient's retirement savings.

As was specified in MacDonald and Cairns (2006), a feature of the model is that individuals make the same plans for retirement across all scenarios; that is, the average retirement age remains relatively consistent. This enables us to compare the results. Since the retirement funds of the older members of the population are significantly larger than those of the younger members, we find that moving pieces of the older members' funds into the younger members' funds decreases the average retirement age. To compensate for this change, we reduce the average contribution rate of all members from $10 \%$ to $8.5 \%$ in this scenario.

In the first scenario, the assets simply change hands at the time of death between individuals of the same age; thus, the transfer is not treated as a cashflow that changes the level of demand for a particular asset, such as pension benefit payouts, investment contributions and asset reallocations. In the second scenario, however, the leakage creates a change in asset demand that must be accounted for in our feedback model.

\section{Feedback Model}

We now introduce a basic model as a starting point to understanding the retirement patterns' circular relationship with asset prices and wage growth. In Section 4.1, we define the relevant notation from the original model. We also introduce some further notation that is necessary to describe the feedback model, and we show how it incorporates into the original model. We proceed to explain the details of the feedback model in Section 4.2. At the end of Section 4.2.2, we present a flow chart that illustrates the full feedback model that we explain throughout this section. Section 4.3 gives the feedback model's parameter estimates. 


\subsection{Introduction and Notation}

The purpose of this section is to present clearly the timing of the feedback system within the evolving levels of wages, financial asset prices and wealth. We accomplish this by describing the original model and incorporating further "feedback" notation. We begin by presenting the wage formulas, then move to the asset price dynamics and finish with the wealth accumulation equations.

To express the methodology of the feedback model, we require two new instants in time to accompany $t$ :

$t^{--}$: instant in time immediately prior to the exiting of the newly retired participants from the workforce and the addition of new workers.

$t^{-}:$instant in time:

- after the salaries have been adjusted on account of the change in labour force participation and

- immediately prior to the change in asset demand.

$t$ : instant in time after

- bequests have been paid out and any associated asset leakage occurs,

- contributions and pension payments have been made,

- and the value of assets have been adjusted on account of excess demand.

The following list of notation represents the economic processes, $x_{1}(t), \ldots, x_{5}(t)$, in the asset accumulation model. This list was given in MacDonald and Cairns (2006) to describe the dynamics of the original model.

$x_{1}(t)$ : Instantaneous risk-free nominal rate of interest at time $t$;

$x_{2}(t)$ : The $\log$ total return on equities from time 0 to time $t$;

$x_{3}(t)$ : Instantaneous risk-free real rate of interest at time $t$;

$x_{4}(t)$ : The consumer price index (CPI) log growth from time 0 to time $t$;

$x_{5}(t)$ : The log real return on wages from time 0 to time $t$. 
We let $S(t)$ represent the value at time $t$ of an investment of $S(0)$ in equities at time 0 . Similarly, $H(t)$ represents the value at time $t$ of an investment of $H(0)$ at time 0 in perpetual index-linked bonds with reinvestment of coupon payments. The proportion of wealth invested in the risky asset, $S(t)$, is represented by $\alpha$, leaving a proportion $(1-\alpha)$ allocated to the low risk asset, $H(t)$.

To present the dynamics of feedback model in the clearest manner, we will present a static investment strategy scenario where all bequests are distributed among surviving members of the deceased's age group. This scenario requires the fewest formulae. We will comment in Section 4.2.2, however, how the equations would have been altered if the individuals elected to move their assets at retirement or if the deceased had left their inheritance to only age groups 20 through 55 .

\subsubsection{The Original Wage Dynamics}

We first describe the wage growth of the original model in relation to the three dates $t^{--}, t^{-}$and $t$. In the absence of feedback, the wage growth is made-up of general wage inflation and merit increases. General wage inflation comprises two parts: price inflation and real wage growth. The salary of a participant in age group $x$ before any retirements is defined as $Y_{x}\left(t^{--}\right)$. The next formula describes the change in salary from times $t-1$ to $t^{--}$:

$$
\begin{aligned}
Y_{x}\left(t^{--}\right) & =Y_{x-1}(t-1) \frac{m\left(x-x_{e}\right)}{m\left(x-x_{e}-1\right)} e^{x_{4}\left(t^{--}\right)+x_{5}\left(t^{--}\right)-\left(x_{4}(t-1)+x_{5}(t-1)\right)} \\
& =Y_{x-1}(t-1) \frac{m\left(x-x_{e}\right)}{m\left(x-x_{e}-1\right)} \frac{C P I\left(t^{--}\right)}{C P I(t-1)} e^{x_{5}\left(t^{--}\right)-x_{5}(t-1)}
\end{aligned}
$$

where merit growth, represented by $m\left(x-x_{e}\right)$, is a function of the worker's length of employment since entry at age $x_{e}$.

Retirements and the employment of new workers are assumed to occur between times $t^{--}$and $t^{-}$. Without the feedback model, $Y_{x}(t)=Y_{x}\left(t^{-}\right)=Y_{x}\left(t^{--}\right)$. With the feedback model, as will be given in Section 4.2.1, salaries are adjusted to reflect the change in the size of the labour force between times $t^{--}$and $t^{-}$(that is, there is no affect between times $t^{-}$and $t$, so $x_{5}(t)=x_{5}\left(t^{-}\right)$and $\left.x_{4}(t)=x_{4}\left(t^{-}\right)\right)$. If we assume that CPI growth is not affected by the feedback $\left(x_{4}\left(t^{-}\right)-x_{4}\left(t^{--}\right)=0\right)$, then $x_{5}\left(t^{-}\right)-x_{5}\left(t^{--}\right)$represents the wage adjustment due to feedback created by a change in the labour force size. Section 4.2.1 will explain our method of modelling the feedback associated with the fluctuating size of the labour force. 


\subsubsection{The Original Dynamics of Equity and Index-Linked Bonds}

We next describe the dynamics of the financial asset prices, as they occurred in the original model, but using the three new dates $t^{--}, t^{-}$and $t$. The value of equities, $S(t)$, changes according to the formula:

$$
S\left(t^{--}\right)=S(t-1) e^{x_{2}\left(t^{--}\right)-x_{2}(t-1)} .
$$

In addition, the total return on index-linked bonds, $H(t)$, is given by:

$$
H\left(t^{--}\right)=H(t-1) \frac{C P I\left(t^{--}\right)}{C P I(t-1)}\left(\frac{1+\sum_{T=t+1}^{\infty} P_{3}\left(x_{3}\left(t^{--}\right), t, T\right)}{\sum_{T=t}^{\infty} P_{3}\left(x_{3}(t-1), t-1, T\right)}\right) .
$$

In our model, any fund account activity occurs between times $t^{-}$and $t$, such as pension benefit payouts, investment contributions, asset leakage and asset reallocations. We model the financial market feedback so that the excess demand for each asset influences its price between times $t^{-}$and $t$.

Assuming the asset prices respond to feedback only between times $t^{-}$and $t$ (that is, $x_{2}\left(t^{-}\right)=x_{2}\left(t^{--}\right), x_{3}\left(t^{-}\right)=x_{3}\left(t^{--}\right)$and $x_{4}\left(t^{-}\right)=x_{4}\left(t^{--}\right)$), we can rewrite equations (7) and (8) as:

$$
S\left(t^{-}\right)=S(t-1) e^{x_{2}\left(t^{-}\right)-x_{2}(t-1)}
$$

and

$$
H\left(t^{-}\right)=H(t-1) \frac{C P I\left(t^{-}\right)}{C P I(t-1)}\left(\frac{1+\sum_{T=t+1}^{\infty} P_{3}\left(x_{3}\left(t^{-}\right), t, T\right)}{\sum_{T=t}^{\infty} P_{3}\left(x_{3}(t-1), t-1, T\right)}\right) .
$$

In the original model, $S(t)=S\left(t^{-}\right)$and $H(t)=H\left(t^{-}\right)$, but neither are equal under the feedback model unless there is no change in the demand for that particular asset. Section 4.2.2 will describe the formulas that determine the magnitude of the feedback.

\subsubsection{The Original Dynamics of Pension Wealth}

We assume the member's decision to retire or not depends on the provisional pension wealth at time $t^{--}$, which is made-up of assets before their prices are adjusted on account of excess demand. Combining $S(t)$ and $H(t)$, along with the two instants in time, $t^{--}$and $t^{-}$, the following equation explains the pension account accumulation from time $t-1$ to $t^{--}$for a participant in age group $x$ :

$$
\mathrm{W}_{x}\left(t^{--}\right)=\mathrm{W}_{x-1}(t-1)\left[\alpha \frac{S\left(t^{--}\right)}{S(t-1)}+(1-\alpha) \frac{H\left(t^{--}\right)}{H(t-1)}\right] \frac{1}{{ }_{1} \mathrm{p}_{x-1}},
$$


where $1 /{ }_{1} \mathrm{p}_{x-1}$ in equation (11) represents the redistribution of bequests among surviving members of each age group (see Section 3.4).

Members decide to retire between times $t^{--}$and $t^{-}$if their provisional wealth, given in equation (11), exceeds the threshold for retirement according to the retirement model (see Section 3.1). Otherwise, they remain in the workforce.

\subsection{Feedback Model Formulas}

Having established the model's basic notation in Section 4.1, we now describe how the actions of the pension plan members influence the economic state variables. Given that there is feedback, Table 1 shows the evolution of theses variables at each sub-step $t^{--}, t^{-}$and $t$. We describe the details behind each change throughout this section.

\begin{tabular}{l|ccc}
\hline & Equities & Index-Linked Bonds & Salaries \\
& $S(t)$ & $H(t)$ & $Y(t)$ \\
\hline$t^{--}$ & $S\left(t^{--}\right)$ & $H\left(t^{--}\right)$ & $Y\left(t^{--}\right)$ \\
$t^{-}$ & $S\left(t^{-}\right)=S\left(t^{--}\right)$ & $H\left(t^{-}\right)=H\left(t^{--}\right)$ & $Y\left(t^{-}\right) \neq Y\left(t^{--}\right)$ \\
$t$ & $S(t) \neq S\left(t^{--}\right)$ & $H(t) \neq H\left(t^{--}\right)$ & $Y(t)=Y\left(t^{-}\right)$ \\
\hline
\end{tabular}

Table 1: Economic state variables at each sub-step.

We begin by explaining the wage feedback, then proceed to describe the financial asset feedback. In both cases, the procedure followed by the feedback model is to:

- measure the excess demand for labour and assets created between times $t^{--}$ and $t$ (we use $\theta$ to represent the change in demand), then

- use this information to adjust the economic state variables (we calculate the adjustment using the elasticity parameter $\kappa$ ).

\subsubsection{Wage Feedback Formulas}

A high dependency ratio, in the context of our model, benefits the workers since it indicates that workers can afford earlier retirement ages. From the perspective of the economy, however, this could induce a labour shortage. In such a scenario, our feedback model postulates that salaries would increase. On the other hand, 
if older workers found that they had insufficient assets to retire, the dependency ratio would drop and the saturated labour force could cause salaries to fall. We assume, therefore, that an expanding supply of labour is a source of negative wage growth.

In each simulated year, the feedback model functions by first adjusting the workers' wages proportionally to the percentage change in the size of the entire workforce. To measure the change in the number of workers, let:

$I_{x}\left(t^{-}\right)$: working status indicator for an individual in age group $x$ at time $t^{-}$( 0 if retired by time $t^{-}$and 1 if working);

The number of workers at time $t^{-}$is:

$$
\sum_{x=x_{e}}^{x=x_{u}} I_{x}\left(t^{-}\right) l_{x}
$$

and the size of the labour force at time $t^{-}$relative to time $(t-1)^{-}$is equal to:

$$
\theta_{Y}=\frac{\sum_{x=x_{e}}^{x=x_{u}} I_{x}\left(t^{-}\right) l_{x}}{\sum_{x=x_{e}}^{x=x_{u}} I_{x}\left((t-1)^{-}\right) l_{x}} .
$$

In equation (12), the numerator includes new entrants and takes account of retirements between times $t^{--}$and $t^{-}$.

If we assume that, between times $t^{--}$and $t^{-}$, the incremental percentage change in wages is proportional to the incremental percentage change in labour supply, then we can define $\kappa_{Y}(<0)$ as the elasticity of wages with respect to labour supply and:

$$
\kappa_{Y} \ln \theta_{Y}=\ln \frac{Y_{x}\left(t^{-}\right)}{Y_{x}\left(t^{--}\right)} .
$$

Adding this to equation (6), the feedback model revises the salary for each working participant in age group $x$ between times $t^{--}$and $t^{-}$according to the next formula:

$$
\begin{aligned}
Y_{x}\left(t^{-}\right) & =Y_{x}\left(t^{--}\right) \theta_{Y}^{\kappa_{Y}} \\
& =Y_{x-1}(t-1) \frac{m\left(x-x_{e}\right)}{m\left(x-x_{e}-1\right)} \frac{C P I\left(t^{--}\right)}{C P I\left((t-1)^{-}\right)} e^{x_{5}\left(t^{--}\right)-x_{5}\left((t-1)^{-}\right)} \theta_{Y}^{\kappa_{Y}} \\
& =Y_{x-1}(t-1) \frac{m\left(x-x_{e}\right)}{m\left(x-x_{e}-1\right)} \frac{C P I\left(t^{-}\right)}{C P I\left((t-1)^{-}\right)} e^{x_{5}\left(t^{-}\right)-x_{5}\left((t-1)^{-}\right)}
\end{aligned}
$$

where $C P I\left(t^{-}\right)=C P I\left(t^{--}\right)$and $x_{5}\left(t^{-}\right)-x_{5}\left(t^{--}\right)=\kappa_{Y} \ln \theta_{Y}$. 


\subsubsection{Wealth and Asset Price Feedback Formulas}

The process of calculating the feedback adjustment for equity and index-linked bond prices is similar to the feedback model for wages, but somewhat more complicated. According to the widespread theoretical effect from Section 2, a greater demand for either asset would increase the value of any portfolio holding it and vice versa. The feedback model adjusts the prices of equities and bonds based on their respective change in demand. Our task is to first determine the change in asset demand. Let:

$\mathrm{W}_{x}^{S}(t)$ : total invested in equities by an individual in age group $x$ at time $t$;

$\mathrm{W}_{x}^{H}(t)$ : total invested in index-linked bonds by an individual in age group $x$ at time $t$.

Referring back to equation (11), the equity and index-linked bond wealth for an individual in age group $x$ at time $t^{--}$, based on the provisional returns from times $t-1$ to $t$, are:

$$
\mathrm{W}_{x}^{S}\left(t^{--}\right)=\alpha \mathrm{W}_{x-1}(t-1) \frac{S\left(t^{--}\right)}{S(t-1)} \frac{1}{1 \mathrm{p}_{x-1}}
$$

and

$$
\mathrm{W}_{x}^{H}\left(t^{--}\right)=(1-\alpha) \mathrm{W}_{x-1}(t-1) \frac{H\left(t^{--}\right)}{H(t-1)} \frac{1}{{ }_{1} \mathrm{p}_{x-1}} .
$$

To determine the change in asset demand, we must measure the cashflows into and out of the equity and bond pension accounts. The cashflows are:

- the payment of pension benefits for retired members $\left(I_{x}\left(t^{-}\right)=0\right.$, which includes the new retirees at time $t^{-}$),

- the investment of contributions by working members $\left(I_{x}\left(t^{-}\right)=1\right)$,

- in the case of the second inheritance decision scenario, the receipt of inheritance for age groups 20 to 55 and the associated asset liquidation and increase to pension accounts,

- the rebalancing of assets to maintain a static investment strategy and

- in the case of a shift to the less risky asset at retirement in the second investment scenario, the reallocation of funds among assets according to a changing investment strategy. 
Note that the upcoming formulae reflect the static investment strategy scenario where all bequests are distributed among surviving members of the deceased's age group; the formulae do not, therefore contain the third and fifth cashflow. We will present the other scenarios and their formulae at the end of this section.

The cashflows occur between times $t^{-}$and $t$ and they are based on the newly adjusted asset prices. This creates a circular dependence between the actual change in demand and the level of feedback since they are both calculated from the other. Owing to this circular dependance, we measure each asset's provisional change in demand to calculate the feedback. We do so by basing the cashflows that should occur between times $t^{-}$and $t$ on:

- the provisional asset values that have not yet been adjusted by the change in demand $\left(S\left(t^{-}\right)\right.$and $\left.H\left(t^{-}\right)\right)$and

- the provisional annuitization interest rate $\left(x_{3}\left(t^{-}\right)\right)$.

We determine the asset supply at time $t^{--}$using equations (14) and (15). The provisional wealth at time $t^{-}$for a member of age group $x$ is:

$$
\begin{aligned}
\mathrm{W}_{x}\left(t^{-}\right)= & \mathrm{W}_{x-1}(t-1)\left[\alpha \frac{S\left(t^{-}\right)}{S(t-1)}+(1-\alpha) \frac{H\left(t^{-}\right)}{H(t-1)}\right] \frac{1}{{ }_{1} \mathrm{p}_{x-1}} \\
& \times\left[1-\frac{\left(1-I_{x}\left(t^{-}\right)\right)}{\ddot{a}_{x}^{x_{3}\left(t^{-}\right)}(t)}\right]+\pi Y_{x}\left(t^{-}\right) I_{x}\left(t^{-}\right)
\end{aligned}
$$

In equation (16), the provisional pension wealth for each DC participant accumulates forward between times $t-1$ and $t^{-}$with the return on their investment $\left(\alpha S\left(t^{-}\right) / S(t-1)+(1-\alpha) H\left(t^{-}\right) / H(t-1)\right)$, by the bequests of the deceased $\left(1 /{ }_{1} \mathrm{p}_{x-1}\right)$ and any provisional cashflows. That is, if the member is employed $\left(I_{x}\left(t^{-}\right)=1\right)$, then their provisional wealth also increases with a contribution of $\pi Y_{x}\left(t^{-}\right)$. Otherwise, for a member who is retired $\left(1-I_{x}\left(t^{-}\right)=1\right)$, their provisional pension income payment reduces their accumulated provisional pension wealth by a rate of $1 / \ddot{a}_{x}^{x_{3}\left(t^{-}\right)}(t)$.

The provisional wealth invested in equities and bonds by an individual in age group $x$ at time $t^{-}$is then:

$$
\mathrm{W}_{x}^{S}\left(t^{-}\right)=\alpha \mathrm{W}_{x}\left(t^{-}\right)
$$

and

$$
\mathrm{W}_{x}^{H}\left(t^{-}\right)=(1-\alpha) \mathrm{W}_{x}\left(t^{-}\right)
$$


respectively. It follows that, across the population of 81 age groups, we can define the provisional demand for equities at time $t^{-}$as a proportion of its supply at time $t^{--}$as:

$$
\theta_{S}=\frac{\sum_{x=x_{e}}^{x=x_{u}} \mathrm{~W}_{x}^{S}\left(t^{-}\right) l_{x}}{\sum_{x=x_{e}}^{x=x_{u}} \mathrm{~W}_{x}^{S}\left(t^{--}\right) l_{x}}
$$

Similarly, the ratio of the provisional demand for index-linked bonds at time $t^{-}$as a proportion of its supply at time $t^{--}$is:

$$
\theta_{H}=\frac{\sum_{x=x_{e}}^{x=x_{u}} \mathrm{~W}_{x}^{H}\left(t^{-}\right) l_{x}}{\sum_{x=x_{e}}^{x=x_{u}} \mathrm{~W}_{x}^{H}\left(t^{--}\right) l_{x}} .
$$

If we let $\kappa_{S}(>0)$ represent the elasticity of the equity price with respect to its demand, then equity prices change in the following way, givena provisional change in demand ratio of $\theta_{S}$ :

$$
\begin{aligned}
S(t) & =S\left(t^{-}\right) \theta_{S}^{\kappa_{S}} \\
& =S(t-1) e^{x_{2}\left(t^{-}\right)-x_{2}(t-1)} \theta_{S}^{\kappa_{S}} \\
& =S(t-1) e^{x_{2}(t)-x_{2}(t-1)},
\end{aligned}
$$

where $x_{2}(t)-x_{2}\left(t^{-}\right)=\kappa_{S} \ln \theta_{S}$.

We apply the same model to the index-linked bond process, with the exception that we define the elasticity of the index-linked bond price with respect to its demand in the market as $\kappa_{H}(>0)$ :

$$
\begin{aligned}
H(t) & =H\left(t^{-}\right) \theta_{H}^{\kappa_{H}} \\
& =H(t-1) \frac{C P I\left(t^{-}\right)}{C P I(t-1)}\left(\frac{1+\sum_{T=t+1}^{\infty} P_{3}\left(x_{3}\left(t^{-}\right), t, T\right)}{\sum_{T=t}^{\infty} P_{3}\left(x_{3}(t-1), t-1, T\right)}\right) \theta_{H}^{\kappa_{H}} \\
& =H(t-1) \frac{C P I(t)}{C P I(t-1)}\left(\frac{1+\sum_{T=t+1}^{\infty} P_{3}\left(x_{3}(t), t, T\right)}{\sum_{T=t}^{\infty} P_{3}\left(x_{3}(t-1), t-1, T\right)}\right),
\end{aligned}
$$

where $C P I(t)=C P I\left(t^{-}\right)$and we choose $x_{3}(t)$ to satisfy the identity ${ }^{3}$ :

$$
1+\sum_{T=t+1}^{\infty} P_{3}\left(x_{3}(t), t, T\right)=\left(1+\sum_{T=t+1}^{\infty} P_{3}\left(x_{3}\left(t^{-}\right), t, T\right)\right) \theta_{H}^{\kappa_{H}} .
$$

\footnotetext{
${ }^{3}$ Since $x_{3}(t)$ is an autoregressive process, the adjustment from $x_{3}\left(t^{-}\right)$to $x_{3}(t)$ makes a material difference to the distribution of $x_{3}(t+1)$. In contrast, for example, $x_{5}(t)$ follows a random walk so that the adjustment from $x_{5}\left(t^{-}\right)$to $x_{5}(t)$ has no impact on what happens in the future.
} 
Returning to equation (11) and including the feedback model, the next formula describes the accumulation of the portfolio wealth from times $t-1$ to $t$ for a participant in age group $x$ :

$$
\begin{aligned}
\mathrm{W}_{x}(t)= & \mathrm{W}_{x-1}(t-1)\left[\alpha \frac{S\left(t^{-}\right)}{S(t-1)} \theta_{S}^{\kappa_{S}}+(1-\alpha) \frac{H\left(t^{-}\right)}{H(t-1)} \theta_{H}^{\mathrm{K}_{H}}\right] \frac{1}{1 \mathrm{p}_{x-1}} \\
& \times\left[1-\frac{\left(1-I_{x}\left(t^{-}\right)\right)}{\ddot{a}_{x}^{x_{3}(t)}(t)}\right]+\pi Y_{x}\left(t^{-}\right) I_{x}\left(t^{-}\right) \\
= & \mathrm{W}_{x-1}(t-1)\left[\alpha \frac{S(t)}{S(t-1)}+(1-\alpha) \frac{H(t)}{H(t-1)}\right] \frac{1}{1 \mathrm{p}_{x-1}}\left[1-\frac{\left(1-I_{x}\left(t^{-}\right)\right)}{\ddot{a}_{x}^{x_{3}(t)}(t)}\right] \\
& +\pi Y_{x}\left(t^{-}\right) I_{x}\left(t^{-}\right) .
\end{aligned}
$$

The following flow chart and adjoining comments present the full model that we have explained throughout this section. While Table 1 indicated the asset values at each point in time, the flow chart details the order of each event that contributes to the feedback: 


\section{Time $t^{--}$}

$\downarrow$

Actual retirement decisions based on provisional asset prices and salaries ${ }^{(a)(b)}$

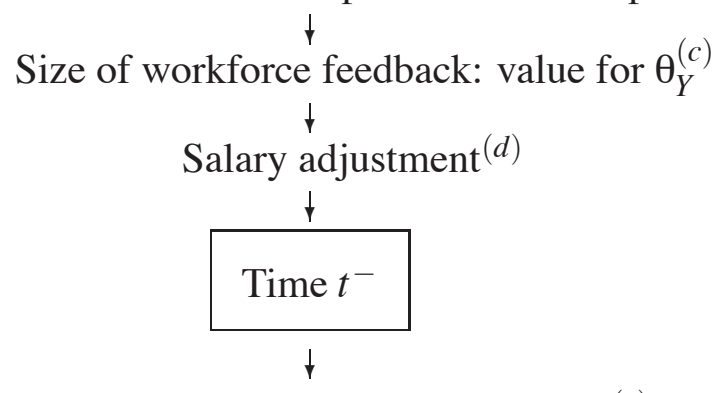

Provisional demand for each asset ${ }^{(e)}$

$\downarrow$
Values for $\theta_{S}(f)$ and $\theta_{H}(g)$
$\downarrow$
Asset price feedback
$\downarrow$

The value of the pension accounts are updated with the newly adjusted asset $\operatorname{prices}^{(j)}$

$\downarrow$

The pension account is altered by the actual cashflows into and out of the fund ${ }^{(k)}$

Time $t$

(a): Provisional asset values, $S\left(t^{--}\right), H\left(t^{--}\right)$, and salaries $Y\left(t^{-}\right)$.

(b): The retirement decision, based on the myopic retirement model, is calculated with the provisional wealth (see equation (11)).

(c): See equation (12).

$(d)$ : See equation (13).

(e): Based on the provisional prices, we calculate the change in asset demand between times $t^{-}$and $t$. The cashflows that contribute to a new level of asset demand are due to the pension account benefit payouts and investment contributions, as well as the rebalancing and reallocation of the assets. See equations (16), (17) and (18). Another source of cashflow is the payout and the associated investment and liquidation of inherited assets, which we discuss below. 
$(f)$ : See equation (19).

$(g)$ : See equation $(20)$.

(h): See equation (21).

(i): See equation (22).

$(j)$ : See equation (24).

$(k)$ : The pension fund contributions and benefit payouts are based on the adjusted asset prices (see equation (24)).

We will now comment on the formula modifications required for other scenarios. First, the use of a fixed $\alpha$ in the preceding formulas implies that the investment strategy is static. If the investment strategy changes at retirement, then the $\alpha$ notation would be replaced by $\alpha_{I_{x}(t-1)}$ in equations (14), (15) (16), (17), (18) and (24) so that $\alpha_{1}$ is the risky asset allocation before retirement and $\alpha_{0}$ is the allocation after retirement.

Secondly, had we wished to change the inheritance decision model so that the bequests were left only to survivors between ages 20 and 55, then equation (16) would change to:

$$
\begin{aligned}
\mathrm{W}_{x}\left(t^{-}\right)= & \left(\mathrm{W}_{x-1}(t-1)+0.1 \times\left\{\sum_{x=x_{e}}^{x=x_{u}} \mathrm{~W}_{x}(t-1) l_{x 1} \mathrm{q}_{x}\right\} / \sum_{x=20}^{x=55} l_{x}\right) \\
& \times\left[\alpha \frac{S\left(t^{-}\right)}{S(t-1)}+(1-\alpha) \frac{H\left(t^{-}\right)}{H(t-1)}\right] \\
& \times\left[1-\frac{\left(1-I_{x}\left(t^{-}\right)\right)}{\ddot{a}_{x}^{x_{3}\left(t^{-}\right)}(t)}\right]+\pi Y_{x}\left(t^{-}\right) I_{x}\left(t^{-}\right)
\end{aligned}
$$

if $x=20$ to 55 , otherwise:

$$
\begin{aligned}
\mathrm{W}_{x}\left(t^{-}\right)= & \mathrm{W}_{x-1}(t-1)\left[\alpha \frac{S\left(t^{-}\right)}{S(t-1)}+(1-\alpha) \frac{H\left(t^{-}\right)}{H(t-1)}\right] \\
& \times\left[1-\frac{\left(1-I_{x}\left(t^{-}\right)\right)}{\ddot{a}_{x}^{x_{3}\left(t^{-}\right)}(t)}\right]+\pi Y_{x}\left(t^{-}\right) I_{x}\left(t^{-}\right) .
\end{aligned}
$$

Equation (24) would be altered with the same changes. In addition, $1 /{ }_{1} \mathrm{p}_{x-1}$ would be removed from equations (14) and (15). Finally, the denominators of 
equations (19) and (20) would be altered to include the total bequests before they are distributed - that is, before any asset leakage occurs:

$$
\begin{aligned}
\theta_{S} & =\frac{\sum_{x=x_{e}}^{x=x_{u}} \mathrm{~W}_{x}^{S}\left(t^{-}\right) l_{x}}{\sum_{x=x_{e}}^{x=x_{u}}\left(\mathrm{~W}_{x}^{S}\left(t^{--}\right) l_{x}+\alpha \mathrm{W}_{x}(t-1) l_{x} \frac{S\left(t^{--}\right)}{S(t-1)} 1 \mathrm{q}_{x}\right)} \\
& =\frac{\sum_{x=x_{e}}^{x=x_{u}} \mathrm{~W}_{x}^{S}\left(t^{-}\right) l_{x}}{\sum_{x=x_{e}}^{x=x_{u}} \mathrm{~W}_{x}^{S}\left(t^{--}\right) l_{x-1}}
\end{aligned}
$$

and

$$
\begin{aligned}
\theta_{H} & =\frac{\sum_{x=x_{e}}^{x=x_{u}} \mathrm{~W}_{x}^{H}\left(t^{-}\right) l_{x}}{\sum_{x=x_{e}}^{x=x_{u}}\left(\mathrm{~W}_{x}^{H}\left(t^{--}\right) l_{x}+(1-\alpha) \mathrm{W}_{x}(t-1) l_{x} \frac{H\left(t^{--}\right)}{H(t-1)} 1 \mathrm{q}_{x}\right)} \\
& =\frac{\sum_{x=x_{u}}^{x=x_{u}} \mathrm{~W}_{x}^{H}\left(t^{-}\right) l_{x}}{\sum_{x=x_{e}}^{x=x_{u}} \mathrm{~W}_{x}^{H}\left(t^{--}\right) l_{x-1}} .
\end{aligned}
$$

\subsection{Estimates for $\kappa_{S}, \kappa_{H}$ and $\kappa_{Y}$}

We experiment with three levels of feedback. In the first and most extreme scenario, we assume that there is a fixed supply of capital in the index-linked bond and equity market, and that our population is living in a closed economy where there are neither overseas nor government sectors. This implies unit elasticity $\left(\kappa_{S}=\kappa_{H}=1\right)$. For example, if the aggregate funds directed towards equity doubles $\left(\theta_{S}=2\right)$, so too would the price:

$$
\begin{aligned}
\frac{S(t)}{S\left(t^{-}\right)} & =\theta_{S}^{\kappa_{S}} \\
& =2
\end{aligned}
$$

so that the total number of units of equity does not change.

Similarly, in our extreme scenario, we let $\kappa_{Y}=-1$ so that there is a fixed level of production and revenue ${ }^{4}$. If the labour force suddenly doubled $\left(\theta_{Y}=2\right)$, then the wages would need to be halved to accommodate the increased supply of

\footnotetext{
${ }^{4}$ Production is not part of our model but lower production per worker is implied by lower wages.
} 
workers with jobs:

$$
\begin{aligned}
\frac{Y_{x}\left(t^{-}\right)}{Y_{x}\left(t^{--}\right)} & =\theta_{Y}^{\kappa_{Y}} \\
& =2^{-1} \\
& =0.5
\end{aligned}
$$

The likelihood of unit elasticity in the financial market was disputed in Section 2. It is also reasonable to suppose that elasticity exists in the level of productivity and revenue. If the size of the workforce increases, output and revenue are also likely to increase, suggesting that unit elasticity of wages with respect to labour supply is an excessive assumption.

We work away from this extreme scenario and first assume that $\kappa_{S}=\kappa_{H}=$ $-\kappa_{Y}=0.5$, then $=0.25$. If the demand for equity, index-linked bonds and employment doubled in the 0.5 feedback scenario, then the price of equity and indexlinked bonds would increase by $41 \%$ while wages would decrease in value by $29 \%$. At 0.25 , the price of equity and index-linked bonds would increase by $19 \%$ and wages would decrease by $16 \%$. We refer to these three scenarios as low, medium and high feedback, although they could possibly all be considered high in reality. We will also consider the scenario of no feedback for the purpose of comparison.

\section{Simulated Results with Feedback}

This section presents the simulated results. Our analysis includes four levels of feedback that we specified in Section 4.3. Following from our discussion in Section 2, we also consider a static and non-static investment strategy. Finally, we investigate two inheritance decision models as discussed in Section 3.4. In total, we simulate 12 scenarios - four levels of feedback for each of the following three populations (A, B and C):

Population A : the population homogeneously holds a non-static investment strategy and inheritance arising from the deceased is re-distributed to the survivors within their respective cohorts;

Population B : the population homogeneously holds a static investment strategy throughout their lifetimes and inheritance arising from the deceased is redistributed to the survivors within their respective cohorts; 
Population C: the population homogeneously holds a non-static investment strategy and inheritance is distributed evenly across members in cohorts aged 20 to 55 .

Beginning in Section 5.1, the preliminary results of the simulation indicate that the feedback model creates lower wage returns and consequently applies an upward pressure on the mean dependency ratio. For fairer comparison between the feedback and original model results, we will make an adjustment to the assetaccumulation model parameters to realign the rates with their original average. In Section 5.2, we will analyze the population dependency ratio results at the four levels of feedback for Population A. Section 5.3 examines this population's retirement dynamics over time. Section 5.4 presents the same four scenarios, but for Population B. Lastly, Section 5.5 tests the second inheritance decision model in Population C.

Sections 5.2 , 5.3, 5.4 and 5.5 reveal that incorporating feedback has a smoothing effect on the dependency ratio volatility. The best results occur when the supply of capital and production is fixed $\left(\theta_{S}=\theta_{H}=\theta_{Y}=1\right)$. Despite the substantial improvement, however, there still remains instability in the dependency ratio.

\subsection{Preliminary Results}

This section contains the feedback model's initial effects on the results. We explain how the feedback alters the economic processes in the asset-accumulation model so that they no longer match their historical averages. We consequentially re-calibrate the original model to compensate for this side-effect.

To illustrate the response of the asset returns to the introduction of the feedback model, we present the simulated dynamics of a population of DC members who homogeneously allocate their pension funds to index-linked bonds at retirement and who, upon death, redistribute their wealth to the survivors in their respective cohorts (Population A ). For eleven investment strategies, Figure 1 graphs the mean dependency ratio over a 4,500 year simulation against its standard deviation. We choose a longer run as opposed to several shorter ones so that the results are less influenced by initial conditions. The best outcomes are those with a high mean dependency ratio with low volatility, indicating early retirement ages among happy citizens while still maintaining a stable labour force participation in the population. We plot the efficient frontier for each feedback scenario, creating four efficient frontiers in total: one for each of the three levels of feedback and another for the model without the inclusion of feedback. To avoid clutter, only the 


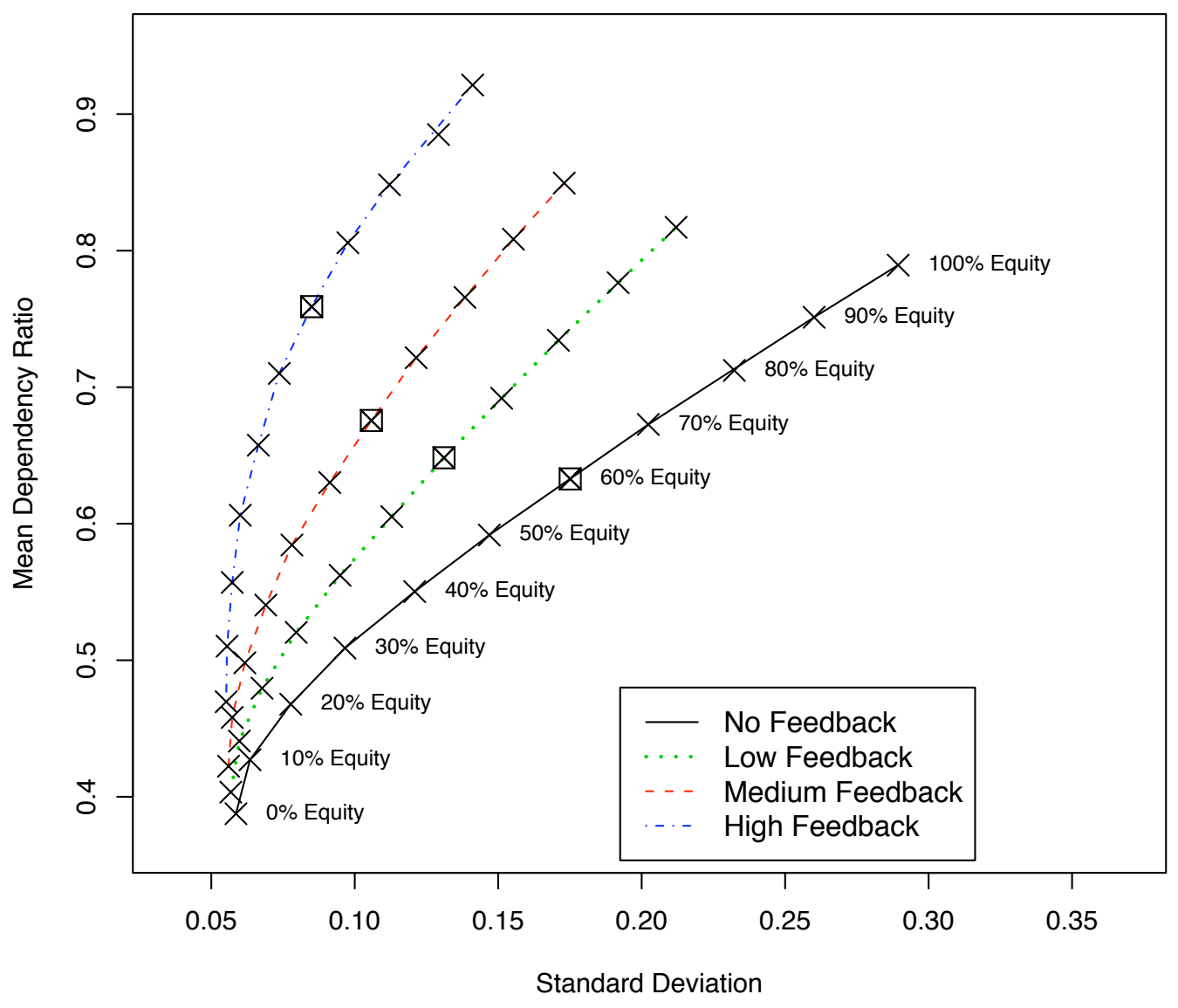

Figure 1: The simulated opportunity sets for Population A, generated by eleven different asset allocation strategies. The graph shows the four efficient frontiers corresponding to each feedback level: 0.25 (dotted line), 0.5 (dashed line), 1 (dotted and dashed line) and no feedback (solid line). In Section 5.3, we will examine more closely the retirement dynamics of the results marked by squares. 
scenario without feedback has its eleven portfolios, indicated by an "X", marked by its equity content (and the remaining portion of each portfolio is invested in index-linked bonds).

Our first observation is that feedback drives up the mean dependency ratio for all investment strategies. This occurs as a result of the the annual recalculation of the instantaneous risk-free real rate of return $\left(x_{3}(t)\right)$, as Section 4.2.2 discussed in a footnote. The adjustments from $x_{3}\left(t^{-}\right)$to $x_{3}(t)$ are positive on average. The altered dynamics of $x_{3}(t)$ affects $x_{4}(t)$ (the CPI process), generating slower wage growth since wages are primarily moved by inflation in our economic model. In fact, in the high feedback scenario, the average wage growth drops from over $3 \%$ to nearly $-6 \%$ when funds are initially only invested in equities and to $-5.25 \%$ when they are initially only invested in index-linked bonds. In our stochastic model, reduced salary growth gives rise to earlier retirement ages and, consequently, higher dependency ratios. This reaction is on account of the enhanced appeal of the retirement pension relative to the slowly growing salary ${ }^{5}$.

There are several forces affecting the index-linked bond return - it is both dampened by the lower inflation as well as boosted by the overall higher real rate of return $\left(x_{3}(t)\right)$. Another influence is the feedback itself, which dampens the returns on index-linked bonds and equities. For example, consider a pension account completely invested in equities where $\kappa_{S}=1, x_{2}(t)-x_{2}(t-1)=0.10$ for four years, and there are neither contributions nor pension payments. Without the feedback feature, the original model would produce the following progression of wealth, $W_{x}(t)$, for a participant in age group $x$ at $t=0$ :

\begin{tabular}{c|c}
\hline Time & $W_{x+t}(t)$ \\
\hline 0 & 1 \\
1 & 1.11 \\
2 & 1.22 \\
3 & 1.35 \\
4 & 1.49 \\
\hline
\end{tabular}

If we include the feedback feature and assume a $20 \%$ decline in equity demand for two years, followed by two years of $20 \%$ increases (and vice versa), the wealth accumulation is modified as the next table demonstrates:

\footnotetext{
${ }^{5}$ See Section 4.7 in MacDonald (2007) for a more complete explanation.
} 


\begin{tabular}{c|c|cc|cc}
\hline Time & $W_{x+t}(t)$ & $\theta_{S}$ & $W_{x+t}(t)$ & $\theta_{S}$ & $W_{x+t}(t)$ \\
\hline & 1 & & 1 & & 1 \\
1 & 1.11 & 0.8 & 0.88 & 1.2 & 1.33 \\
2 & 1.22 & 0.8 & 0.78 & 1.2 & 1.76 \\
3 & 1.35 & 1.2 & 1.04 & 0.8 & 1.56 \\
4 & 1.49 & 1.2 & 1.37 & 0.8 & 1.37 \\
\hline
\end{tabular}

The inclusion of the feedback model, therefore, decreases the overall return on equities. To keep the results on par with our original model for fairer comparison, we would need to increase $x_{2}(t)-x_{2}(t-1)$ by $2.03 \%$ in the two feedback scenarios, to produce the following:

\begin{tabular}{c|c|cc|cc}
\hline Time & $W_{x+t}(t)$ & $\theta_{S}$ & $W_{x+t}(t)$ & $\theta_{S}$ & $W_{x+t}(t)$ \\
\hline & 1 & & 1 & & 1 \\
1 & 1.11 & 0.8 & 0.90 & 1.2 & 1.35 \\
2 & 1.22 & 0.8 & 0.81 & 1.2 & 1.83 \\
3 & 1.35 & 1.2 & 1.1 & 0.8 & 1.65 \\
4 & 1.49 & 1.2 & 1.49 & 0.8 & 1.49 \\
\hline
\end{tabular}

Without the adjustment, the inclusion of feedback causes the equity's total return to fall below its historical average. In our preliminary results, these lower rates of return should delay the workers' retirements, causing the mean dependency ratio to shrink, but the influence of the negative wage growth masks this repercussion and actually reverses the effects.

We re-calibrate the original asset-accumulation model parameters that were specified in MacDonald and Cairns (2006) so that the mean rates of return for equities, index-linked bonds and wages are approximately consistent with the original summary statistics. We adjust the following estimates since they are the key parameters that specifically affect these rates:

$R P_{2}$ : the equity risk premium in excess of the risk-free rate of interest (this was represented by $\sum_{x=1}^{5} \sigma_{2 j} \delta_{x}$ in the original description of the economic process for $x_{2}(t)$ in MacDonald and Cairns (2006)),

$\mu_{3}:$ the real-world long-term mean real rate of interest and

$R P_{4}$ : the inflation-protection premium (this was represented by $\sum_{j=1}^{5} \sigma_{4 j} \delta_{j}$ in the original description of the economic process for $x_{4}(t)$ in MacDonald and Cairns (2006)). 
We modify $R P_{2}, \mu_{3}$ and $R P_{4}$ so that the average returns on the economic processes $x_{2}(t), x_{3}(t)$ and $x_{4}(t)$ return to their original values. Notionally, $\mu_{3}$ is the mean reversion level. As we explained above, the adjustments from $x_{3}\left(t^{-}\right)$to $x_{3}(t)$ from Section 4.2.2 are positive on average. By making the downward adjustment to $\mu_{3}$, the long-term mean of $x_{3}(t)$ is returned to approximately its original value. This adjustment also affects $x_{4}(t)$ by bringing its long-term mean closer to its original value since $x_{4}(t)$ is integrated with both $x_{3}(t)$ and $\mu_{3}$. The adjustment to $\mu_{3}$, however, does not completely correct for the influence of the feedback and we thus adjust the long-term risk premium, $R P_{4}$, so that the long-term mean of $x_{4}(t)$ is also returned to approximately correspond with its original value.

Each investment strategy creates a slightly different level of feedback. To calibrate the model, we choose the align the results of the $60 \%$ equities and $40 \%$ index-linked bonds initial portfolio since we examine the results of this portfolio more closely in later sections. Similarly, moving from a static to a non-static investment strategy, as well as assuming a different inheritance decision model, all produce feedback that alters the economic processes in the asset accumulation model; each scenario, therefore, requires its own parameter adjustments. Having $\kappa_{S}=\kappa_{H}=-\kappa_{Y}=0.25,0.5$ and 1, Tables 2, 3 and 4 present the original and the re-calibrated parameters values for each level of feedback.

\begin{tabular}{c|ccc}
\hline Scenario & $R P_{2}$ & $\mu_{3}$ & $R P_{4}$ \\
\hline Original & $5.28 \%$ & $2.66 \%$ & $-0.44 \%$ \\
0.25 & $7.7 \%$ & $-1.2 \%$ & $-1.34 \%$ \\
0.5 & $10.01 \%$ & $-4.94 \%$ & $-2.23 \%$ \\
1 & $15.18 \%$ & $-11.85 \%$ & $-3.84 \%$ \\
\hline
\end{tabular}

Table 2: Necessary parameter adjustments for the asset-accumulation model with feedback for Population A. 


\begin{tabular}{c|ccc}
\hline Scenario & $R P_{2}$ & $\mu_{3}$ & $R P_{4}$ \\
\hline Original & $5.28 \%$ & $2.66 \%$ & $-0.44 \%$ \\
0.25 & $9.24 \%$ & $-1.11 \%$ & $-1.32 \%$ \\
0.5 & $13.57 \%$ & $-3.55 \%$ & $-1.96 \%$ \\
\hline
\end{tabular}

Table 3: Necessary parameter adjustments for the asset-accumulation model with feedback for Population B.

\begin{tabular}{c|ccc}
\hline Scenario & $R P_{2}$ & $\mu_{3}$ & $R P_{4}$ \\
\hline Original & $5.28 \%$ & $2.66 \%$ & $-0.44 \%$ \\
0.25 & $7.72 \%$ & $-0.7 \%$ & $-1.23 \%$ \\
0.5 & $10.21 \%$ & $-3.9 \%$ & $-1.98 \%$ \\
1 & $16.50 \%$ & $-9.77 \%$ & $-3.35 \%$ \\
\hline
\end{tabular}

Table 4: Necessary parameter adjustments for the asset-accumulation model with feedback for Population C.

We arrive at the appropriate parameters through simulated trial and error. As discussed throughout this section, there is a myriad of repercussions in the stochastic economic model when we include feedback owing to the integrated economic processes. Consequentially, the asset returns for Population $\mathrm{C}$ could not be reconciled to their original values when we attempted unit elasticity ${ }^{6}$. We present, therefore, only the first two levels of feedback for this scenario.

\subsection{Results for Population A}

Using the same scale as Figure 1, Figure 2 graphs the results of the re-calibrated asset-accumulation model. We find that having realigned the economic processes with their original long-term averages successfully returns the dependency ratio averages to approximately their original levels. We can now see clearly that the inclusion of the feedback lowers the dependency ratio volatility, and this improvement increases with the level of feedback. The feedback is strongest when

\footnotetext{
${ }^{6}$ In this scenario, a much great proportion of the population's total fund is invested in equities since the larger accumulated savings of the population's elder members continue to be allocated to equities even after retirement. Owing to the greater role of this volatile and sensitive asset, we were unable to re-calibrate the model for unit elasticity.
} 


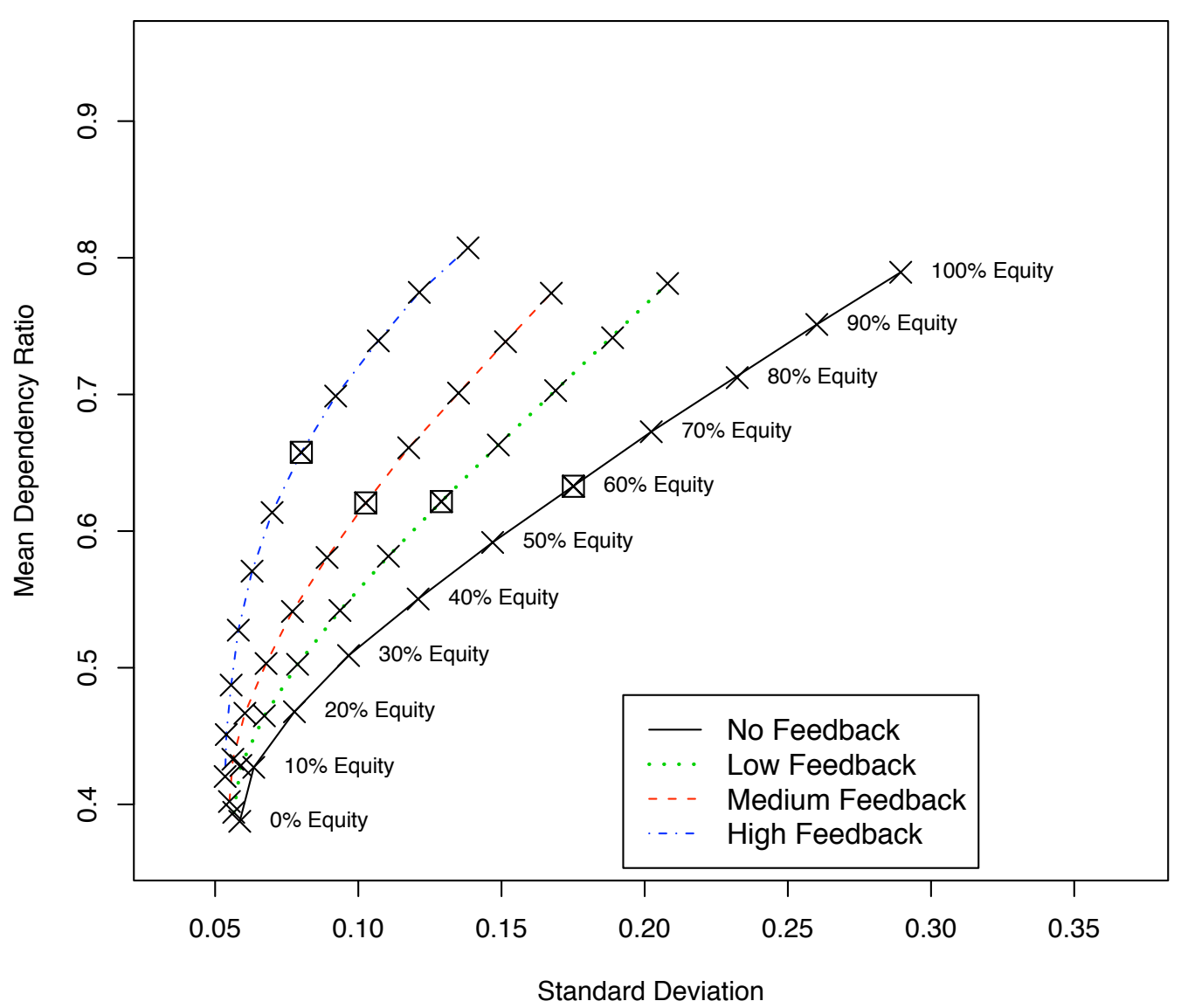

Figure 2: The same simulation as shown in Figure 1, but carried out using a recalibrated asset-accumulation model that accommodates the feedback feature.

$\kappa_{S}=\kappa_{H}=-\kappa_{Y}=1$ and the investment strategy is $100 \%$ equities. The volatility in the dependency ratio is impressively halved in this extreme scenario, reducing it from approximately $29 \%$ to $14 \%$. The $14 \%$ standard deviation, however, could potentially not be low enough.

It is possible that a by-product of the feedback model is a reduction in the equity return risk, thus explaining the decline in the dependency ratio volatility. This is, however, not the cause since the volatility of the log equity returns actually lowers only slightly after the inclusion of feedback when the feedback is strongest. The noteworthy reduction in the dependency ratio fluctuations is indeed attributable to the feedback. 


\subsection{Dependency Ratio Dynamics for Population A}

In this section, we wish to get a fuller picture of the impact of the feedback model and the remaining dependency ratio fluctuation. This section ascertains that, although the feedback mitigates the extreme results that were originally produced, the dependency ratio still remains unstable.

Figure 3 tracks the simulated dependency ratio over the span of 300 years for a population that homogeneously invests in $60 \%$ equities and $40 \%$ indexlinked bonds during employment and $100 \%$ index-linked bonds after retirement and where bequests are inherited evenly by survivors in the deceased's age group (Population A). We examine, therefore, the retirement dynamics of a population whose results are marked by a square in Figure 2.

Moving from plots (a) to (c), the results progressively improve as the feedback becomes stronger. The feedback undoubtedly reduces the fluctuation in the dependency ratio, but perhaps not enough. Even with the most extreme level of feedback in plot (c) where there is unit elasticity, the dependency ratio is still unsteady and ranges between $44 \%$ and $112 \%$ over the simulated period.

\subsection{Dependency Ratio Dynamics for Population B}

Since workers could potentially not reduce their allocation to risky assets on retirement, we next investigate the possible improvement that the feedback feature offers to the dependency ratio dynamics in the scenario that the members maintain a static investment strategy throughout their lifetimes. We find that there is approximately the same level of improvement as for Population A .

Figure 4 plots the same simulation as shown in Figure 3, except the population members in Figure 3 allocate their funds to only index-linked bonds after retirement and those in Figure 4 do not alter from their original investment strategy throughout their lifetimes (Population B). Comparing plots (a) and (b) to those in Figure 3, the inclusion of feedback for Population B has roughly the same smoothing effect on the dependency ratios as for Population A .

\subsection{Dependency Ratio Dynamics for Population C}

Finally, we investigate the reaction of the dependency ratio behavior and the feedback feature to the second inheritance decision model. Figure 5 plots the same simulation as shown in Figure 3 except all bequests are evenly allocated among survivors aged 20 to 55 . 
(a)

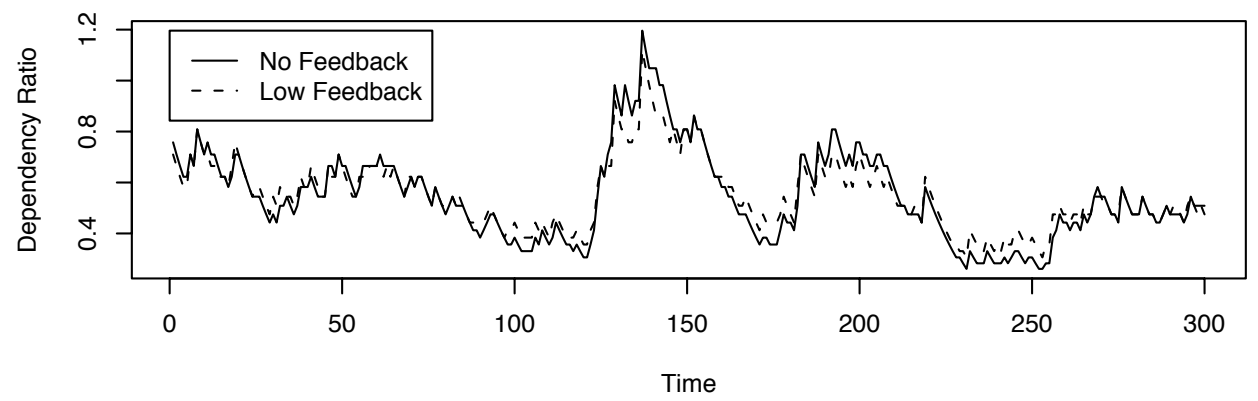

(b)

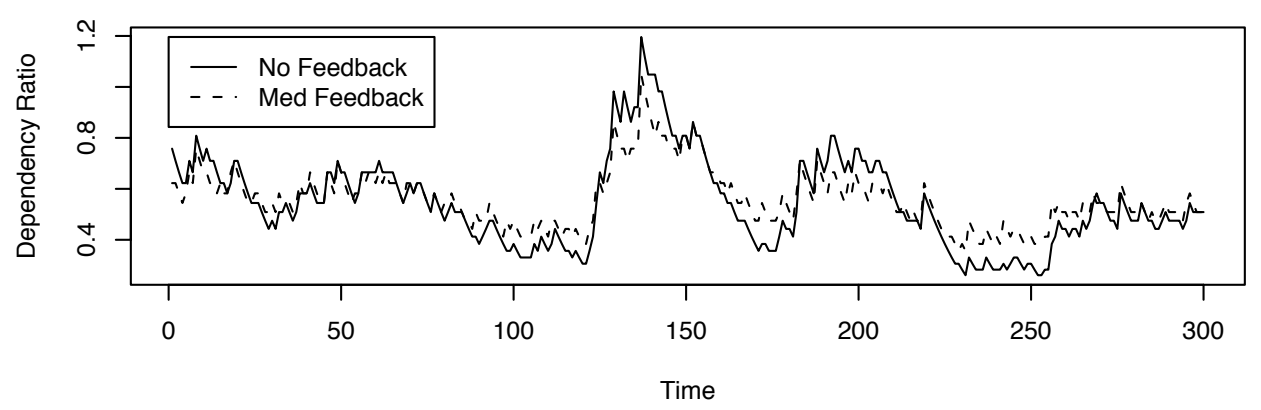

(c)

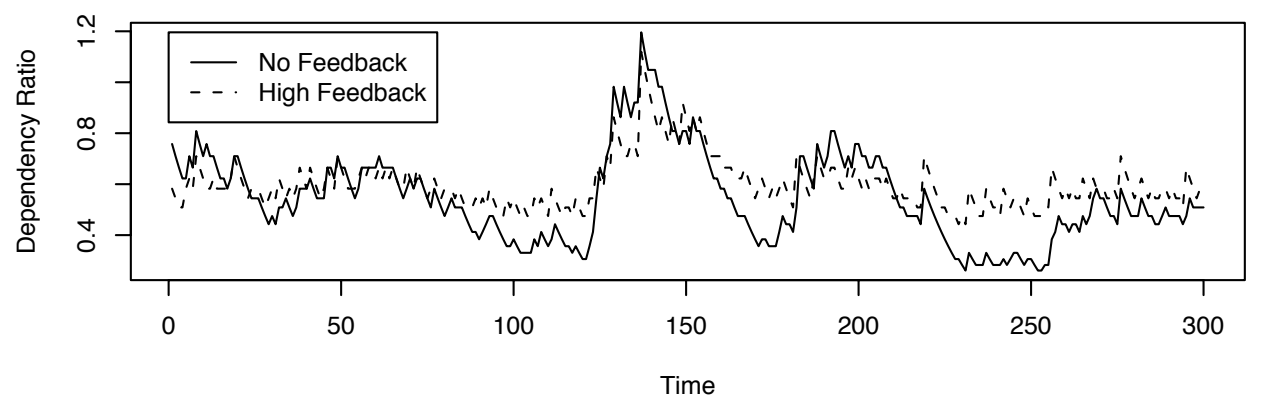

Figure 3: Simulated time series plot of the dependency ratio for Population A with a homogeneous investment strategy of $60 \%$ equity and $40 \%$ index-linked bond during employment and solely index-linked bonds after exiting the workforce. We plot the dependency ratio of the model without feedback (solid line) against the dependency ratio of the model with feedback (dashed line) at the level: (a) low, (b) medium and (c) high. 
(a)

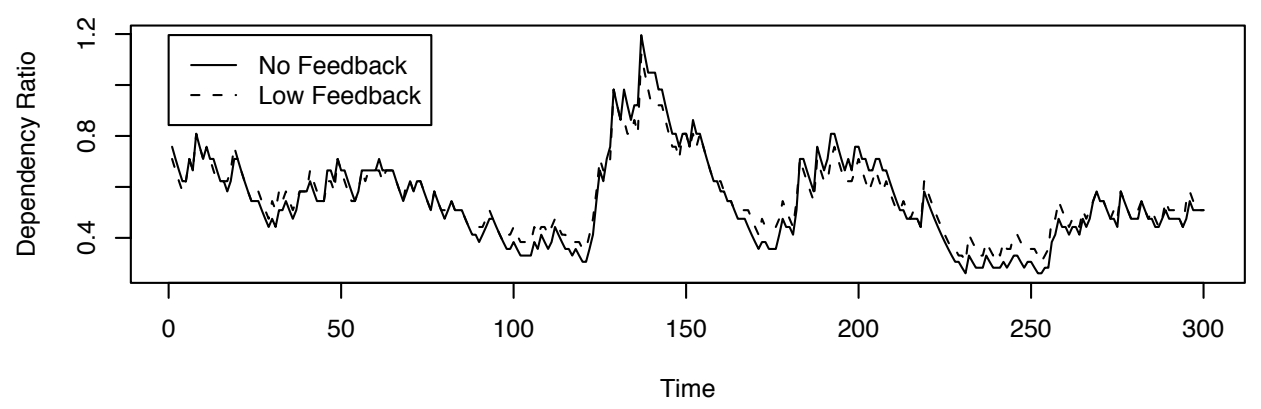

(b)

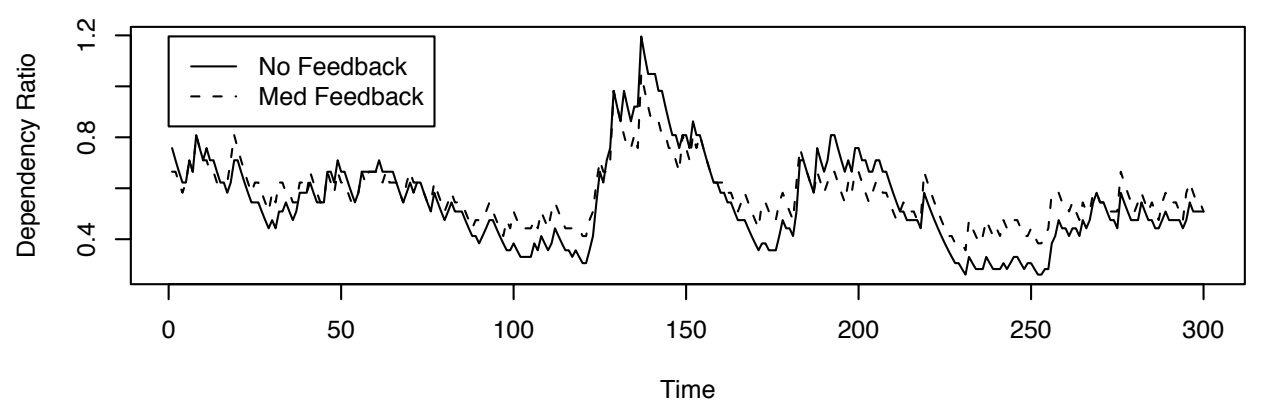

Figure 4: The same simulation as shown in Figure 3, but for Population B. 
(a)

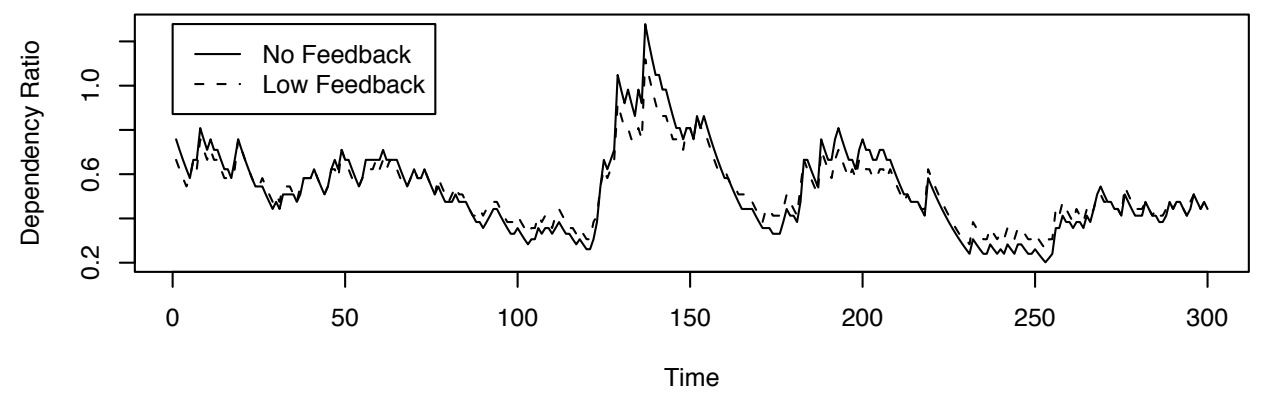

(b)

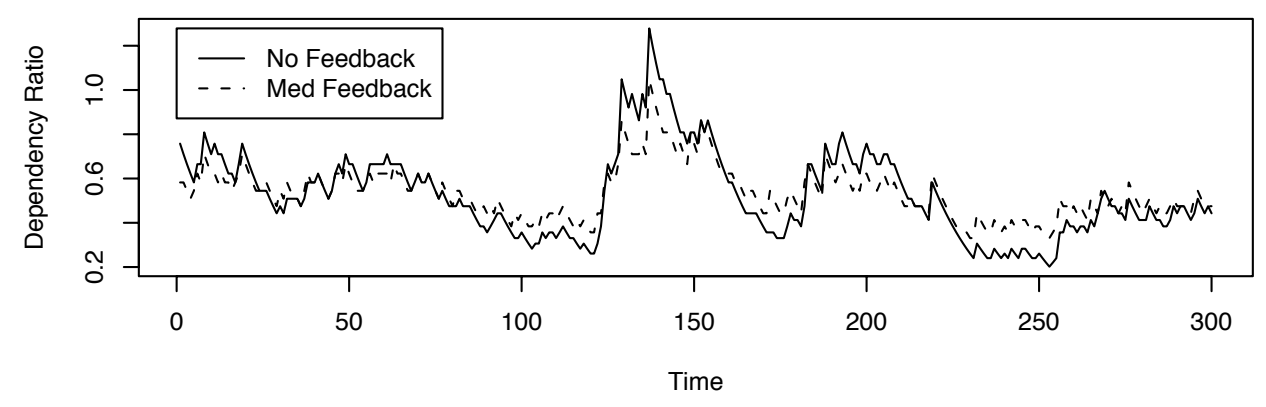

(c)

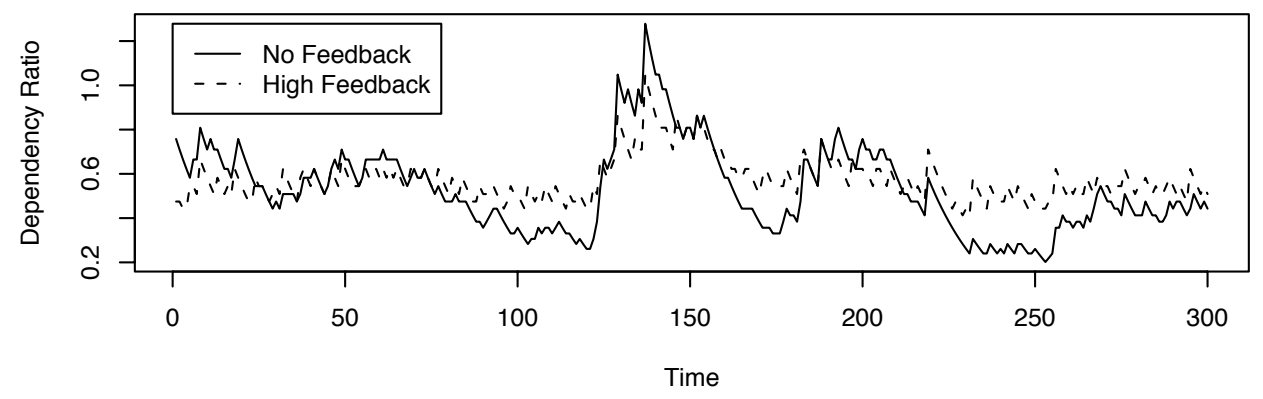

Figure 5: The same simulation as shown in Figure 3, but for Population C. 
Putting feedback aside for a moment, the second inheritance decision model does not improve the behavior of the dependency ratio under the original model. Assuming a $60 \%$ equity and $40 \%$ index-linked bond initial investment strategy and no feedback, the standard deviation is $17.5 \%$ under the first inheritance scenario (Population A ) and 19.3\% under the second (Population C). In this second scenario, a large proportion of the retirement assets of the deceased are liquidated; consequentially, once we include the feedback feature in the model, the heavier asset traffic creates more feedback than in the previous inheritance decision model. Comparing plot (a) to (c) in Figures 3 and 5, the somewhat more flattened feedback results for Population $\mathrm{C}$ illustrate that it is slightly more sensitive to the feedback feature. For example, a medium level of feedback reduces the dependency ratio standard deviation for both Populations A and B by $41 \%$ and by $43 \%$ for Population C. Similarly, unit elasticity reduces the standard deviation of Population A by 54\% and Population C by 56\%. Although the feedback has a slightly more improving effect on the dependency ratio stability than in the other two scenarios, they still remain quite volatile. In the unit elasticity scenario, the dependency ratio spans the range of 0.41 to 1.05 .

\section{Conclusion}

This paper takes another step in our analysis of the possible consequences of a nation-wide DC pension system by simulating the dynamic relationship among population retirement patterns, asset demand and financial market returns, as well as between labour supply and wages. The inclusion of macroeconomic feedback has the beneficial effect of reducing the volatility of the dependency ratio; nevertheless, it only partially dampens the fluctuations and there still remains instability in the labour force participation rate. Our conclusions continue to suggest that a nation-wide DC pension design could potentially pose a threat to the stability of the ratio of workers to retirees from one year to the next and consequently affect the stability of the economy.

Our method is just one of many ways to model feedback. Our purpose is to investigate the first order effect of feedback compared to a benchmark model with no feedback. Alternative formulations might, for example, allow potential retirees to review their retirement decisions once asset prices have been adjusted for feedback. Future work could improve on our DC population modeling by tying together consumption, production and income. In addition, since our feedback

model is a crude first approximation to find market equilibrium, future work could 
incorporate a feedback model that finds the market equilibrium - where the asset prices are adjusted until the supply is equal to the demand.

\section{Acknowledgements}

Both authors would like to thank David Wilkie for his ideas on how to model feedback and his comments on the paper. This research was completed during the $\mathrm{PhD}$ and of Bonnie-Jeanne MacDonald at Heriot-Watt university and while she occupied a Post-Doctoral Position at the University of Waterloo. She wishes to acknowledge the financial support of Heriot-Watt University, the British Council, the Spencer Education Foundation, the American Society for Quality, the North American Society of Actuaries and the Natural Sciences and Engineering Research Council of Canada.

\section{References}

Ang, Andrew, and Angela Maddaloni. 2003. Do Demographic Changes Affect Risk Premiums? Evidence From International Data. National Bureau of Economic Research Working Paper 9677, Cambridge, MA.

Arias, Elizabeth. 2004. United States Life Tables, 2002. National Vital Statistics Reports 53(6): 1-39.

Bosworth, Barry P., Bryant, Ralph C., and Gary Burtless. 2004. The Impact of Aging on Financial Markets and the Economy: A Survey. Working Paper, The Brookings Institution, Washington.

Brooks, Robin J. 2002. Asset Market Effects of the Baby-Boom and Social Security Reform. American Economic Review 92: 402-406.

Brown, Jeffrey R., and Mark J. Warshawsky. 2001. Longevity-Insured Retirement Distributions from Pension Plans: Market and Regulatory Issues. National Bureau of Economic Research Working Paper 8064, Cambridge, MA.

Blake, David, Cairns, Andrew J. G. and Kevin Dowd. 2003. PensionMetrics 2: Stochastic Pension Plan Design During the Distribution Phase. Insurance: Mathematics and Economics 33: 29-47.

Davidoff, Thomas, Brown, Jeffrey R., and Peter A. Diamond. 2005. Annuities and Individual Welfare. The American Economic Review 95(5): 1573-1590. 
Lachance, Marie-Eve. 2003. Optimal Investment Behavior as Retirement Looms. Working Paper, Wharton School, University of Pennsylvania, Philadelphia.

MacDonald, Bonnie-Jeanne and Andrew J. G. Cairns. 2006. The Impact of DC Pension Systems on Population Dynamics. To appear in the North American Actuarial Journal.

MacDonald, Bonnie-Jeanne. 2007. The Impact of Defined Contribution Pension Plans on Population Retirement Dynamics. PhD thesis, Heriot-Watt University. McGill, Dan M., Brown, Kyle N., Haley, John J., and Sylvester J. Schieber. 1996. Fundamentals of Private Pensions. 7th ed. Philadelphia: University of Pennsylvania Press.

OECD, 2005. Ageing and Pension System Reform: Implications for Financial Markets and Economic Policies. OECD Publishing, Paris.

Poterba, James M. 2004. The Impact of Population Ageing on Financial Markets. National Bureau of Economic Research Working Paper 10851, Cambridge, MA.

Poterba, James M., Venti, Steven F., and David A. Wise. 2005. Demographic Change, Retirement Saving, and Financial Market Returns: Part 1. National Bureau of Economic Research Papers on Retirement Research Center Projects NB05-01, Cambridge, MA.

Stock, James H. and David A. Wise. 1990. Pensions, the Option Value of Work, and Retirement. Econometrica 58(5): 1151-1180.

Vasicek, Oldrich E. 1977. An Equilibrium Characterisation of the Term Structure. Journal of Financial Economics 5(2): 177-188. 